\title{
RECAPTURE, TRANSPARENCY, NEGATION AND A LOGIC FOR THE CATUSKOTI
}

\begin{abstract}
ADRIAN KREUTZ
ABSTRACT: The recent literature on Nāgārjuna's catuṣkoți centres around Jay Garfield's (2009) and Graham Priest's (2010) interpretation. It is an open discussion to what extent their interpretation is an adequate model of the logic for the catuskoti, and the Mülamadhyamaka-kārikā. Priest and Garfield try to make sense of the contradictions within the catuskoti by appeal to a series of lattices - orderings of truth-values, supposed to model the path to enlightenment. They use Anderson \& Belnaps's (1975) framework of First Degree Entailment. Cotnoir (2015) has argued that the lattices of Priest and Garfield cannot ground the logic of the catuskoti. The concern is simple: on the one hand, FDE brings with it the failure of classical principles such as modus ponens. On the other hand, we frequently encounter Nāgārjuna using classical principles in other arguments in the MMK. There is a problem of validity. If FDE is Nägärjuna's logic of choice, he is facing what is commonly called the classical recapture problem: how to make sense of cases where classical principles like modus pones are valid? One cannot just add principles like modus pones as assumptions, because in the background paraconsistent logic this does not rule out their negations. In this essay, I shall explore and critically evaluate Cotnoir's proposal. In detail, I shall reveal that his framework suffers collapse of the kotis. Taking Cotnoir's concerns seriously, I shall suggest a formulation of the catuskoti in classical Boolean Algebra, extended by the notion of an external negation as an illocutionary act. I will focus on purely formal considerations, leaving doctrinal matters to the scholarly discourse - as far as this is possible.
\end{abstract}

Keywords: Buddhist philosophy, Catuskoti, Nagarjuna, paraconsistency, philosophy of logic, Graham Priest, speech act theory, recapture problem

\section{THE FOUR CORNERS}

Everything is real and is not real,

Both real and not real,

Neither real nor not real.

This is Lord Buddha's teaching.

(MMK XVIII:8)

KREUTZ, ADRIAN: Department of Philosophy, University of St Andrews, Scotland, UK. Email: adrian_kreutz@icloud.com 
The argument in (MMK XVIII:8) above goes under the name catușoți ${ }^{1}$ (Sanskrit; चतुष्कोटि). It has found its most prominent use in the Madhyamika school ${ }^{2}$ of Buddhism and the writings of Nāgārjuna ${ }^{3}$, and his Mūla-madhyamaka-kārikā (henceforth: MMK). Here is why the catuskoti is enigmatic to contemporary (academic) logic: in the West, following Aristoteles's logic, we encounter the principle of tertium non datur: everything is either true, or false - c'est tout. The catuskoti inflates (while denying) this principle to a quintum non datur: It sates four exhaustive and mutually exclusive possibilities for any proposition: (1) either it holds, (2) it does not hold, (3) it both holds and does not hold, (4) it neither holds nor does not hold - those are the four kotis (which roughly translates as "corners"). A model for the catuskoti has to maintain the mutual exclusivity and exhaustive nature of the kotis - call this the exclusivity/exhaustivity constraint. The reason is twofold: (1) we want to be charitable to the logical abilities to the authors who were using the catuskoti, and (2) is the way the (negative) catuskoti is commonly employed as an argument, supposed to undermine all possible ways a predicate can be attributed to something needs the four kotis to exhaust the logical space, which they can only do if they are mutually exclusive. This argument, which is a kind of reductio argument to reveal the deficiency of the concept in question is called a prasanga argument. The concepts the MMK is dealing with are causation, motion, self, identity and others. In MMK XVIII:8, specifically, the thesis is that 'everything' is 'real'. The four kotis are supposed to exhaust all of the logical space and to state every possible way "reality" can be attributed to the object which is "everything". Hence, the argument sees the anti-thesis that 'everything' is not real, the conjunction of thesis and anti-thesis, and the disjunction of thesis and anti-thesis. As Priest (2010) says:

"The central concern of the MMK is to establish that everything is empty of selfexistence (svabhava), and the ramifications of this fact. The main part of the work consists of a series of chapters which aim to establish, of all the things which one might plausibly take to have svabhava (causes, the self, suffering, etc.), that they do not do so." Priest (2010)

To do that, every possible way something can be has to be ruled out eventually to illuminate their emptiness of self-existence. The "quadruple-wise" exclusivity of the kotis comes as a natural consequence of wanting to establish the exhaustivity of the kotis. Only if none of the kotis is equivalent to the other kotis, only if every koti establishes a distinct possibility, the logical space can be exhausted.

\footnotetext{
${ }^{1}$ For what follows, I will deprive myself of the diacritical of an adequate translation from Sanskrit and write 'catuskoti' instead.

${ }^{2}$ Although, as I argue in a forthcoming article, it is neither limited to Madhyamaka, nor the Indian philosophical milieu. Just like most concepts of Buddhist thinking it has its origins in Hindu texts (or a criticism thereof) and has developed as Buddhism found its way to the East.

${ }^{3}$ For a general introduction to the thinking of Nagarjuna and the history of Buddhist metaphysics and the catuskoti, see Priest (forthcoming).
} 
Let us give a very straight forward model of the catuskoti to see the deficiency of classical logic in this context:

Positive Catuskoti

(1) $A$

(2) $\neg A$

(3) $A \wedge \neg A$

(4) $\neg(A \vee \neg A)$

To make sense of it with the tools of (classical) modern western logic, we first have to drop $(D N ; \neg \neg A \dashv \vdash A)$, i.e. the Principle of Double Negation. If we would not drop DN, koti (3) and koti (4) would collapse, since by De Morgan's Law they are equivalent. Even if they would not collapse, the third koti would still entail both koti (1) and koti (2) - this contradicts their mutual exclusivity.

In Westerhoff's (2009: 4) attempt to rescue the status of classical logic concerning the catuskoti, we find a different type of negation for koti (4), such that koti (3) is no more deducible from (4). He notes that Indian logic (sometimes) distinguishes internal (prayudāsa) from external (prasaja) negation ${ }^{4}$. Historically, the distinction is grammatical; the prasaja-negation negates the verb (as in brāhmana nasti, "This is not Brahmin"), the prayudāsa-negation connects with the noun-phrase (as in abrāhmana asti - "This is a Non-brahmin"). Let us reflect this semantics with a distinction between external and internal negation: whereas the internal negation in any proposition implies the existence of another but different proposition, the external negation does not. The negation in "This bird is not a crane (i.e. a non-crane)" is internal, it implies that the object (the bird) exists, but that it is some other species than a crane, i.e. that the predicate ("crane") does not apply to the object (bird). An external negation of the proposition would say "It is not the case that (this bird is a crane)" - hence, there is no implicature to the existence of anything whatsoever.

Note that every proposition with an internal negation implies the denial of the state-of-affairs in question, but not vice versa. From the fact that there is something that has "bird-ness" but not "crane-ness" in this particular region of space-time under consideration, we can infer that there is nothing that has both "bird-ness" and "craneness". But from that fact that there is nothing that has both "bird-ness" and "craneness", we cannot infer that there is such a thing that has "bird-ness" but no "craneness" since there might be nothing that has "bird-ness", or even nothing at all. Westerhoff applies this distinction to koti (4), arguing that the negation before the parentheses is to be read externally, while the negations in koti (2) and (3) are not. Priest (2010) argues that the negation-move is somewhat ad hoc, and while it holds for kotis (1-3), it cannot hold for koti (4). In any way, it seems arbitrary to distinguish

\footnotetext{
${ }^{4}$ In modern discussions on category mistakes, we find a distinction into choice negation and exclusion negation. This reflects the ancient idea of prayudasa/prasaja. See Routley (1969) as prominent example.
} 
between different negations within the catuskoti, if there is no textual evidence for it. I will pick up the discussion in $\$ 6$ again.

Besides that, the catuskoti contradicts both $(L E M ; A \vee \neg A)$, i.e. the Law of the Excluded Middle, and $(L N C ; \neg(A \wedge \neg A))$, i.e. the Law of Non-Contradiction. We can thus, without being overly reckless, say that the tools of classical logic are slightly limited when consulted to formulate an adequate model of the catuskoti. It is often seen as a last resort to appeal to non-classical logics in which LEM and LNC are not valid, but the catuskoti suggests it. A formal logical system in which the validity of (EXP; $A, \neg A \vdash B$ ), i.e. The Principle of Explosion is denied is, in modern logical terms, paraconsistent. The simplest paraconsistent logic is LP. What to make of koti (1) and koti (2) in light of a paraconsistent logic is an open question: how can we express the classical "just true" and "just false"? ${ }^{5}$ This question will also be picked up here and there throughout this essay. A formal logical system in which (LEM) is dropped is, in modern logical terms, paracomplete. $\mathrm{K} 3$, is arguably the simplest paracomplete $\operatorname{logic}{ }^{6}$.

\section{THE GARFIELD/PRIEST INTERPRETATION}

In the search for an adequate model for the catuskoti Priest (2010) introduces a set of status-predicates and gives an interpretation of those, using a four-valued semantics. He expresses the four kotis with a set of status-predicates: $S=\{T, F, B, N\}$, which evaluate the semantic status of a proposition on a meta-level. Let $T$ be the truthpredicate "is true", $F$ is "is false", $B$ is "both true and false", $N$ is "neither true nor false". $T(A)$ is the proposition "A is true", where $(A)$ is a name for $A$. To define $B, N$ Priest first defines $F$ as $F(A)=T(\neg A)$. Here is how we define the four kotis:
1) $T(A)=T(A) \wedge \neg F(A)$
2) $F(A)=\neg T(A) \wedge F(A)$
3) $B(A)=T(A) \wedge F(A)$
4) $N(A)=\neg T(A) \wedge \neg F(A)$

Taking the exclusivity/exhaustivity constraint into account, the catuskoti can be expressed in the following way:

$$
\begin{aligned}
& \text { Catuskoti }(+): T(A) \vee F(A) \vee B(A) \vee N(A) \\
& \text { Exclusivity Constraint: } \neg(S 1(A) \wedge S 2(A))
\end{aligned}
$$

\footnotetext{
${ }^{5}$ For a recent strategy on how to articulate the "just true/just false" in a paraconsitent logic, termed 'shrieking', see Beall (2013) and a response in Scharp (2018). Note that the 'just-true' problem is merely one instance of the classical recapture problem: how to make sense of cases, where the inconsistency of A and its negation is assumed?

${ }^{6}$ For an introduction to both, see Priest (2001).
} 
The positive catuskoti can be represented by a four-valued lattice in Anderson and Belnap's (1975) logic of First Degree Entailment (FDE). The logic is a sort of combination of the two well-known three-valued logics LP and K3. By assigning a truth value to all the sentences of the language in which the catuskoti is formulated via an interpretation function $v$, such that $v(A) \in\{t, f, b, n\}$, we generate a semantics for the logic. Let the four kotis be represented by this Hasse-Diagram.

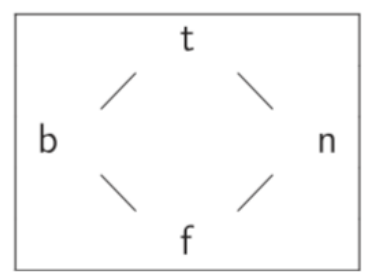

TABLE 1: The positive catuskoti

The behaviour of the standard connectives is defined like this:

The value of disjunction, $v(A \vee B)$, is the least upper bound of $v(A)$ and $v(B)$. The value of the conjunction, $v(A \wedge B)$, is the greatest lower bound of $v(A)$ and $v(B)$.

The value of negation, $v(\neg A)$ otherwise toggles $t$ and $f$ but maps $\{b, n\}$ to itself.

To define validity in many-valued logic, we need to elaborate on the notion of designated value - the values that are preserved in valid arguments.

The set of designated values is $D=\{t, b\}$

Call Priest's logic for the catuskoti FDE(S), where the S stands for the set of statuspredicates.

If the value of $\mathrm{A}$ is designated, $T(A)$ is also designated. If the value of $\mathrm{A}$ is not in $D$, the value of $T(A)=f$

If A takes some value, the statement to the effect that it takes that value is designated. This can be seen by following the diagonal, top left to bottom right on the diagram below.

\begin{tabular}{|l|l|l|l|l|}
\hline $\mathrm{A}$ & $\mathrm{T}\langle\mathrm{A}\rangle$ & $\begin{array}{l}\mathrm{B} \\
\langle\mathrm{A}\rangle\end{array}$ & $\mathrm{F}\langle\mathrm{A}\rangle$ & $\mathrm{N}\langle\mathrm{A}\rangle$ \\
\hline $\mathrm{t}$ & t or $\mathrm{b}$ & $\mathrm{f}$ & $\mathrm{f}$ & f or $\mathrm{b}$ \\
\hline $\mathrm{b}$ & b or $\mathrm{f}$ & t or $\mathrm{b}$ & $\mathrm{b}$ or $\mathrm{f}$ & f or $\mathrm{b}$ \\
\hline $\mathrm{f}$ & $\mathrm{f}$ & $\mathrm{f}$ & $\mathrm{t}$ or $\mathrm{b}$ & $\mathrm{f}$ or $\mathrm{b}$ \\
\hline $\mathrm{n}$ & $\mathrm{f}$ & $\mathrm{f}$ & $\mathrm{f}$ & $\mathrm{t}$ \\
\hline
\end{tabular}


These truth conditions validate the formal statements of the catuskoti and meet the exclusivity/exhaustivity constraint. Consider the formulation if the catuskoti with status-predicates: Catuskoti $(+): T(A) \vee F(A) \vee B(A) \vee N(A)$. Whatever value a proposition takes, that value will be designated (t or b), and hence will be the disjunction. Considering the Exclusivity Constraint: Any statement of the form $S 1(A) \wedge S 2(A)$ will contain a sub-conjunction of the form $T(A) \wedge T \neg(A)$ or $F(A) \wedge \neg F(A)$. So, $\neg(S 1(A) \wedge S 2(A))$ is equivalent to a disjunction which has a part of the form $T(A) \vee T \neg(A)$. Either $A$ is designated, and so is the first disjuncts, or $A$ is not designated but then the second disjuncts is. Therefore, the whole disjunction is designated.

Considering the Exhaustivity Constraint, $\operatorname{FDE}(\mathrm{S})$ avoids the collapse of the kotis: (4) $\neg T(A) \wedge \neg F(A)$ does not collapse into (3) $T(A) \wedge F(A)$ in $\operatorname{FDE}(\mathrm{S})$. To say that $\neg(T(A) \vee F(A))$ is to say, that $\mathrm{A}$ is neither true nor false, to say that $T(A) \wedge F(A)$, is to say that $A$ is both true and false - two very different things. The status-predicates avoid the collapse. It does not collapse, since the biconditional in $\mathrm{FDE}(\mathrm{S})$, just as in LP is not contrapossible. We don't have $\neg T(A) \rightarrow T \neg(A)$. This will be made more precise later on, when I give the collapse argument against Cotnoir's logic for the catuskoti.

A prominent characteristic of the Garfield/Priest interpretation is that it employs a metaphysical distinction that is commonly found in the Madhyamika. Reality is a twofold concept that displays itself through 'conventional reality' (samvrti-satya) and 'ultimate reality' (paramarthra-satya). It describes the world of appearances. This includes material objects, properties, causation, the self, feelings, memories, individuality, identity (etc.), and the erroneous idea that all those things have svahbava. Furthermore, it is the realm of thought, language, and most probably, logic. Nāgārjuna says that claims about conventional reality have all four truth-values of the catuskoti. What to make of that, and whether Nagarjuna, by saying that, is proposing a position on its own is part of the contemporary discourse ${ }^{7}$. Rejecting all four kotis is sometimes called the 'fourfold negation'. There is a corresponding negative catuskoti.

Negative Catuskoti
(1) $\neg A$
(2) $\neg(\neg A)$
(3) $\neg(A \wedge \neg A)$
(4) $\neg(\neg(A \vee \neg A))$

In Priest (2010) we see the negation as a fifth possibility, resulting in a five-valued logic, where the fifth value (e), which stands for emptiness, is the denial of the other four values. One might wonder whether this threatens the exhaustivity of the kotis on the outset? Indeed, it does when one operates on the level of conventional reality only. One has to bear in mind that the fifth value corresponds to the ultimate reality, the four kotis hence exhaust the logical space of the conventional reality, whereas the

\footnotetext{
${ }^{7}$ See, again, Westerhoff $(2007,2009)$ or Kreutz (forthcoming).
} 
fifth values exhausts the logical space of the ultimate reality. This is the reason why the pairwise exclusivity of the kotis isn't threatened either. The designated values remain $\{t, b\}$, since (e) expresses that a claim should neither be accepted nor denied. It can, therefore, not be designated. For more on the semantics of the negative catuskoti, please see Priest (2010).

\section{Catuskoti(-): $T(A) \vee F(A) \vee B(A) \vee N(A) \vee E$}

The negative catuskoti emphasises the view that ultimate reality is essentially ineffable. Claims about ultimate reality are ineffable since ultimate reality is inaccessible from the standpoint of conventional reality, and since our language is a language of conventional reality, truth about the fundamental reality cannot be expressed with the vocabulary of conventional language. They are asserted only for the purpose of designation. The 'Four Extremes' (Sanskrit; चतुरन्त) is a particular application of the logical form of the catuskoti to a metaphysical thesis. Garfield/Priest suggest a fifth truth-value (e) which has none of the four truth values and is the denial of all the kotis.

The Four Extremes, The Fifth Value

1) Being $^{8}$

2) Non-Being

3) Being and Non-Being

4) Neither Being, nor Non-Being

5) None of the above (e)

By disproving all conceivable possibilities with (e), Nāgārjuna traces the middle path between being and non-being. Adding (e), makes our logic five-valued, where the fifth value is supposed to be incompatible with the other four. Call the resulting logic $\mathrm{FDE}_{\mathrm{e}}$.

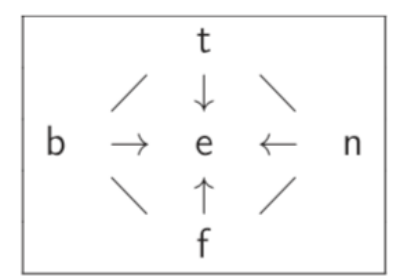

TABLE 2: The negative catuskoti

\footnotetext{
${ }^{8}$ The technical term for 'being' in Buddhist literature is 'dharma', the bare phenomena of the world. The truth-value (e) corresponds to the view that everything is empty 'sunya', empty of essence, or selfexistence 'svahbava'. For more information about those terms, see Westerhoff (2007), or Priest (forthcoming).
} 
But how do we proceed in our logical analysis now? How can a sentence expressed in conventional reality receive the value (e)? Priest suggests a new valuation function $\mu$, which maps all values in the set $\{t, f, b, n\}$ to (e), such that $\mu(v(A)=e$, then $\mu(v(\neg A)=\mu(v(A \wedge B)=\mu(v(A \vee B))))=e$. The new truth-value should not be designated. It neither tells us to accept the status of the other claims nor their negations, and can therefore not be designated. If it were designated, the negative catuskoti would represent a trivialism. Priest (2010) holds this to be untenable. The connectives for (e) will put out (e) in every instance, the arrows in TABLE 2 shall represent this. The negation of (e) is of course (e).

The bearer of (e) has to be reconceptualised. We are no more talking about statements, such as the positive catuskoti does, we are talking about states-of-affairs. Whereas the positive catuskoti is talking about statements made in and about conventional reality, the negative catuskoti is talking about ultimate reality itself. Whereas we had a semantic thesis with the positive catuskoti, we now have a metaphysical thesis.

Reading Nāgārjuna through the lens of Zen teaching, Garfield/Priest say that realizing that the distinction between fundamental reality and ultimate reality is itself merely conventional corresponds to the process of enlightenment. One becomes enlightened once one realizes that the conventional reality fails to exist ultimately. But not only that. One has to realize that the emptiness of ultimate reality is itself empty - the reflective arrow in TABLE 3 shall represent this. Call it "the emptiness of emptiness".

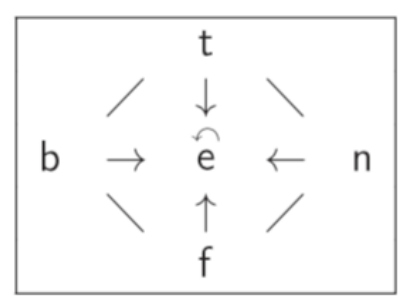

TABLE 3: The emptiness of emptiness

For the phenomena to exist at all, is for them to be empty of inherent existence. Realizing their emptiness is realizing their existence. From this point, one can jump into the abyss of enlightenment, knowing that reality will not bottom out, as the Zen Teachers would say. The soteriological end-goal of enlightenment is therefore not the extinction of self and the reality, as the negative catuskoti might suggest, it rather lies in the achievement of a deep understanding of the inherent nature of reality - which is emptiness. Archiving this understanding does not change the world of appearance, but arguably the appearance of the world. Once awakened, the usefulness of the negative catuskoti vanishes, and so $\mu=0$, i.e. it stops mapping all the values in the set $\{t, f, b, n\}$ to (e), the set $\{t, f, b, n\}$, which represents conventional reality remains. 


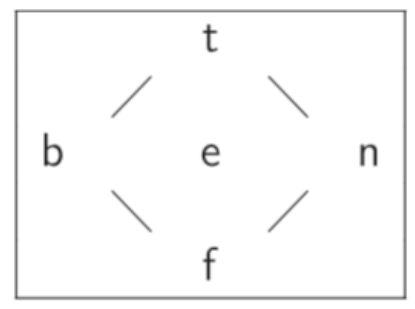

TABLE 4: Awakening

Although, as I argue in Kreutz (forthcoming), I take the systematics described by Garfield/Priest as an adequate conceptual model for the path towards enlightenment, as described in Chan/Zen, and especially the jūgyūzu (Jap. 十牛図, Eng. Ten Ox Herding Pictures). I can see no trace of it in Nagarjuna. As the discussion is, in this context at least, limited to Nagarjuna's use of the catuskoti, I find it hard to accept the story around the negative catuskoti. As far as I am aware, it is predominantly the prasanga-argument which employs the negative catuskoti, and it is that way in which the negative catuskoti is used in Nagarjuna.

\section{VALIDITY AND FDE}

Even if Priest is right in modelling the catuskoti and the process of awakening with $\mathrm{FDE}(\mathrm{S})$ and $\mathrm{FDE}_{\mathrm{e}}$, several difficulties appear. It is well known that several classical principles, such as modus ponens, modus tollens and hypothetical syllogism fail in FDE. Hence, they also fail in the Garfield/Priest logic for the catuskoti. Yet, as Cotnoir points out, Nāgārjuna regularly employs the above-mentioned inferences in the $\mathrm{MMK}^{9}$. To give you one apparent example of a modus ponens in MMK:

\section{Modus Ponens: $A \supset B, A \vDash B$}

When there is change, there is motion. Since there is change in the moving, motion is in that which is moving. (MMK 2.2)

Since the material conditional is a hidden disjunction (by definition, $v(A \supset B)=v(\neg A \vee B))$, there is a counterexample to it in FDE: take $v(A)=b$ and $v(B)=f$. Remember, $D=\{t, b\}$. The second premise is designated, since $v(A)=b$. What about the first premise? Negation does not toggle $b$, so $v(\neg A)=b$. The way that disjunction is defined, the least upper bound of $b$ and $f$ is $b$, thus $v(\neg A \vee B)=b$. Since $v(A \supset B)=v(\neg A \vee B))$, the first premise ' $v(A \supset B)$ ' is also designated. By stipulation, $v(B)=f$, and is thus undesignated. Hence, we have designated premises, but an undesignated conclusion. Modus ponens fails.

\footnotetext{
${ }^{9}$ For present purposes, it will suffice to give the counterexample to one of the classical principles only. For the other counterexamples, see Cotnoir (2015).
} 
Similar counterexamples can be found for modus tollens, disjunctive syllogism and hypothetical syllogism, and similar instances of Nāgārjuna employing them in the MMK can be found as well. The Garfield/Priest interpretation has a serious problem. If FDE is Nāgārjuna's logic of choice, those arguments are invalid. There are (at least) two ways to handle this problem: find a paraconsistent and paracomplete logic that recaptures the classical principles, or find a classical logic which meets the exclusivity/exhaustivity constraint ${ }^{10}$. One thing is certain: FDE, as it is, is too weak to be a genuine logic for the MMK.

\section{COTNOIR'S SOLUTION TO THE RECAPTURE PROBLEM}

Cotnoir's proposal on how to accommodate the weakness of FDE is upfront. He takes his inspiration from suggestions in Deguchi, Priest and Garfield (2008) who understand the positive catuskoti as a tool, supposed to undermine the conventional reality, not as a characterization of the ontological status of the conventional perspective itself. On their reading, contradictions applied to conventional reality are merely prima facie ${ }^{11}$.

Cotnoir goes on to disambiguate the contradictions between the conventional and the ultimate perspectives. He suggests that the positive catuskoti blends both perspectives, so that contradictions on the conventional level dissolve. He introduces an alternative lattice which is still four-valued. He also retains $\{t, b\}$ as designated values. The mayor difference is that it is formulated in plain Boolean Algebra, with the result that the crucial classical principles are accommodated. In detail, he takes the truth-values to be ordered pairs such that both perspectives are represented in the truth-value. The first member of the pair answers "is it conventionally true?" with affirmation ' 1 ' or denial ' 0 ', the second answers "is it ultimately false?" with affirmation ' 1 ' or denial ' 0 '. With this, he re-produces the four corners of the catuskoti. The possibilities are: $(1,1),(1,0),(0,1),(0,0)$. One example: $(1,1)$ means conventionally true, and ultimately false. Disjunction and conjunction are invariably defined as least upper bound and greatest lower bound. One difference is that negation toggles not only $(0,1)$ and $(1,0)$, but also $(1,1)$ and $(0,0)$. The semantics for negation thus denies the possibility of contradictions on the conventional level. Since Cotnoir retains $D=\{t, b\},(1,1)$ and $(1,0)$ are designated. Validity $\left(\vDash_{\mathrm{B} 4}\right)$ is defined in

\footnotetext{
${ }^{10}$ One could of course think of Nagarjuna as a logical pluralist who is using one logic hear, and another logic there. A problem with this approach is the fact that Nagarjuna (as did all the other philosophers of his time an area) did not use any logic at all. What, I guess, motivates Cotnoir's point here is that we, again, want to be charitable to Nagarjuna's logical abilities. We can guess that he would have realised that his way to formulate arguments, especially the prasanga on the one side, and the modus-ponens on the other, do not go together.

${ }^{11}$ For this proposal to work, eventually, we need to establish a connection between the four kotis (i.e. stating all the ways something could be), and an undermining of conventional reality. It looks like, stating things as they are, on its own, is not enough to establish anything like an undermining of conventional reality. As I argue in Kreutz (forthcoming), there is no logical connection between the kotis and what Cotnoir would describe as the undermining of conventional reality, which, argumentum e contrario, is the establishing of absolute reality.
} 
the usual designation-preserving way. The semantics generates are purely classical propositional logic - a four-valued Boolean Algebra (call it: B4). It validates all the classical principles that FDE is too weak to validate ${ }^{12}$.

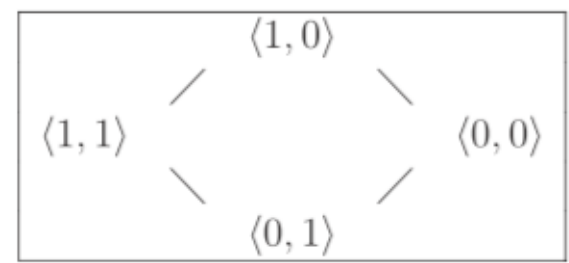

TABLE 5: Cotnoir's Lattice

This interpretation of the catuskoti, which is suggested in Garfield and Priest (2003) and Garfield (1995) relies on the Tibetan teacher Tsongkhapa's (1357-1419) reading of the catuskoti, who excessively engaged with the ultimate/conventional distinction. Considering $M M K X V I I I: 8$,

Everything is real [conventionally] and is not real [ultimately].

Both real [conventionally] and not real [ultimately],

Neither real [ultimately] nor not real [conventionally].

This is Lord Buddha's teaching.

See how Tillemann (1997) comments on this interpretation:

Indisputably, Tsong kha pa's interpretation offers advantages in terms of its logical clarity, but as an exegesis of Madhyamaka, his approach may seem somewhat inelegant, since it obliges us to add words almost everywhere in Madhyamaka texts. Remarkably, Tsong kha pa himself accomplishes this project down to its most minute details in his commentary on the Madhyamakakarikas-perhaps at the price of sacrificing the simplicity of Nagarjuna's language. Hence, is there a more elegant interpretation of the tetralemma...?

The same applies to Cotnoir's proposal. It offers a certain logical clarity on the cost of metaphysical confusion. Throwing the ultimate and conventional perspective together takes away the initial appeal to different levels of reality and dilutes the distinction into positive and negative catuskoti.

Furthermore, and most importantly, what looks like the perfect logic for Nāgārjuna cannot account for the negative catuskoti, used as a prasanga argument. As this is the predominant role of the catuskoti within the MMK, I take Cotnoir's proposal to be misguided (with respect to the MMK) To see that, remember that the B4-semantics implies that no proposition and its negation can both be ultimately notfalse. But from the ultimate perspective, the catuskoti says that being true is not the

${ }^{12}$ Also, the "just-true problem" is solved, since truth is conventionally identical to un-falsity, and falsity to un-truth. 
same as being not-false. As Cotnoir acknowledges, the B4-semantics is useful only for the positive catuskoti. It is still FDE(e) that is the adequate logic for the negative catuskoti, but that again suffers from the recapture problem.

\section{WHY COTNOIR'S PROPOSAL FAILS}

I shall now argue that B4 is an infelicitous choice even for a model of the positive catuskoti: B4 is unable to meet the exclusivity and exhaustivity constraint. I shall first address two concerns that one might have with B4 and motivate a plausible reply to those on behalf of Cotnoir. This is not to say that those responses are the only worth considering - there may as well be better responses. Maybe even responses that would suppress the collapse-argument that I will put forward. Nevertheless, I take my responses on behalf of Cotnoir to be the most natural and obvious.

\section{First Concern: Classical Operators}

B4 works with the classical operators, and as we saw in the discussion in $\S 1$, the classical operators lack the expressive power to meet the exclusivity/exhaustivity constraint. Priest (2010) introduces the ideas of several commentators who have tried to meet the constraint with the apparatuses of classical logic. I have mentioned Westerhoff's approach, who tries to avoid the collapse of the kotis by resorting to different types of negation. Priest's concerns remain pressing, and the move to paraconsistency seems appropriate. This shall not mean that the debate is settled, or that any formulation of the catuskoti with (slightly altered) classical operators is ultimately going to fail, or that other non-classical logic (such as relevant-logic) cannot be successfully employed. But since those matters are contentious, I want to highlight the most obvious reply at this point - just to return to them later in my own proposal.

Since we know that adding a set of status-predicates to FDE does satisfying work, we can try adding status-principles to B4. The corners of the B4-lattice get assigned their corresponding status-predicate ${ }^{13}: \mathrm{B}=(1,1), \mathrm{T}=(1,0), \mathrm{F}=(0,1), \mathrm{N}=(0,0)$. I take this to be the most compelling way to introduce status predicates. Call the resulting logic 'B4S'. This move has one downside: the status-predicates cannot reflect the levels of reality we find in the suggested metaphysics in the way the ordered pairs do. But, this is no surprise as we already know that B4 is not the right logic for the (as often interpreted) ontologically-loaded negative catuskoti. Anyways, we can try to include the distinction into metaphysical realms of reality in our model: one way to introduce status-predicates to B4 which seems natural if one wants to reflect the different levels of reality is this,

$$
\begin{gathered}
(1,1)=\left(\mathrm{T}_{\mathrm{C}}, \mathrm{F}_{\mathrm{U}}\right) \\
(1,0)=\left(\mathrm{T}_{\mathrm{C}}, \neg \mathrm{F}_{\mathrm{U}}\right)
\end{gathered}
$$

${ }^{13}$ See TABLE 5 


$$
\begin{gathered}
(0,1)=\left(\mathrm{F}_{\mathrm{C}}, \mathrm{F}_{\mathrm{U}}\right) \\
(0,0)=\left(\mathrm{F}_{\mathrm{C}}, \neg \mathrm{F}_{\mathrm{U}}\right)
\end{gathered}
$$

where the indexed $\mathrm{C}$ reflects conventional reality, and the indexed $\mathrm{U}$ reflects ultimate reality ${ }^{14}$.

The problem here is that, as far as common interpretation of Buddhist texts goes, it is only the conventional type of truth that language can express. Whatever happens in ultimate reality, and hence also the truth- and falsehood about ultimate reality, remains ineffable. If this is right, whatever kind of metalinguistic status-predicate we use for Cotnoir's ordered pairs, it reduces to a statement about conventional reality, and if so, cannot express the four corners of the catuskoti - it would reduce to $\mathrm{T}_{\mathrm{C}}$ and $\mathrm{F}_{\mathrm{C}}$. This is in effect the criticism that the Tsongkhapa interpretation that we have looked at above is facing, too.

One resort would be to hold that we can have a status predicate for ultimate reality, but that it cannot be used to speak truly or falsely, but that it only expressed things of the form $\mathrm{N}_{U}(A)^{15}$. The worry here is the same as above: such a combination of status-predicates is only capable of expressing two possibilities, $\left(\mathrm{T}_{\mathrm{C}}, \mathrm{N}_{\mathrm{U}}\right)$ and $\left(\mathrm{F}_{\mathrm{C}}\right.$, $\mathrm{N}_{\mathrm{U}}$ ). Hence, the only way to introduce a metalinguistic status-predicate for Cotnoir's ordered pair is by taking the ordered pair to be a conjoint claim: " $\mathrm{A}$ is conventionally true and ultimately not false" which is reflected in the ordered pair $(1,0)$ and will be expressed with the status-predicate $\mathrm{T}$.

Assessing the first proposal: the move has the down-side of not reflecting the levels of reality we find in the suggested metaphysics in the way the ordered pair does. Nevertheless, I take the first concern concerning the classical operators to be alleviated. It is, as we see in FDE, not necessary to reflect the metaphysics in the way the ordered pair does. Moreover, the metaphysics on which Cotnoir is referring itself springs from a contentious interpretation of ancient texts as the quotes above suggest.

\section{Second Concern: Transparency}

The truth-predicate $T$ in $\operatorname{FDE}(\mathrm{S})$, as Priest defines it, satisfies the unrestricted Tschema - i.e. it is transparent. A transparent truth predicate $T$ is one that, paired with some quotation device '[]', allows for any well-formed-formula $A$, for the claim $T(A)$ to be substituted for A or vice versa, in all extensional contexts, in all arguments without change in validity.

\section{Unrestricted T-Schema (UT):T[A] $\leftrightarrow A$}

One could argue that transparency of the truth-predicate is something that Nāgārjuna would not have endorsed. Priest explicitly addresses this thought:

\footnotetext{
${ }^{14}$ Thanks to Aaron Cotnoir for suggesting this assignment of status-predicates.

${ }^{15}$ We find such a proposal in Priest (2010: 24)
} 
I do not know of any Indian textual sources that endorse this [the unrestricted T-schema], but it seems so natural and obvious that it is plausible that it was taken for granted. In Western philosophy, it has been problematized by paradoxes such as the Liar. But, again as far as I know, there is no awareness of these in early Indian philosophy. (Priest 2010)

The unrestricted T-Schema has been problematized by paradoxes of self-reference since, together with classical logic, via the principle of explosion, it leads into trivialism - the claim that everything is true. In other words: any arbitrary statement is equivalent to its own truth-predication. In the case of the catuskoti, we would suffer collapse of the kotis if our logic is classical (as B4S is) and the truth-predicate transparent (which it most probably is, as well, if it inherits the status-predicates from $\mathrm{FDE}(\mathrm{S}))$. To see this, follow the subsequent reasoning:

$\begin{array}{ll}\text { Unrestricted T-Schema: } & T[A] \leftrightarrow A \\ \text { Contraposition: } & \neg T[A] \leftrightarrow \neg A \\ \text { Unrestricted T-Schema } & T[\neg A] \leftrightarrow \neg A \\ \text { Transitivity } & T[\neg A] \leftrightarrow \neg T[A]\end{array}$

If this reasoning is right, the second koti $F(A) \wedge \neg T(A)$ is equivalent to $F(A) \wedge \neg T(A)$, which is $T(\neg A) \wedge T(\neg A)$, which is $F(A)$. The same happens with $T(A)$. Since we have defined the third koti as $T(A) \wedge F(A)$, it is obvious that koti (3) collapses into koti (1) and (2) again. Moreover, koti (4) is equivalent to koti (3). The catuskoti suffers complete collapse. The price one has to pay for an unrestricted Tschema is the replacement of the classical biconditional with a non-contrapossible non-classical one. Priest avoids the problem by going non-classical. The biconditional in $\mathrm{FDE}(\mathrm{S})$ is not contrapossible, it thus avoids the collapse of the kotis.

Since B4 is classical, semantically closed, and (to make sense of the exclusivity/exhaustivity constraint), inherits the transparent truth-predicate from $\mathrm{FDE}(\mathrm{S})$, it leads to trivialism. This is indeed an unacceptable consequence, but a very obvious one ${ }^{16}$.

However, let this not be the end of the story for B4. It does not have to be irrevocable that an unrestricted T-schema plays havoc with classical logic. New developments, named Strict-Tolerant Conception of Truth ${ }^{17}$, introduce a transparent truth-predicate which does not lead to trivialism in a classical framework. It might also be possible to introduce a set of status-predicates with a restricted T-schema i.e. with an opaque truth-predicate ${ }^{18}$. The advocate of the latter position would have to tell a story about paradoxes of self-reference, but I don't want to rule out such a

\footnotetext{
${ }^{16}$ Which is why we might question whether the MMK requires accepting transparent truth. Indeed, there is perhaps nothing in the MMK itself that requires transparent truth, but it is such a plausible idea that there is nothing in the MMK that would speak against it. In fact, it doesn't really matter, the collapse argument I shall put forward doesn't rely on it, as a later point will show. Again, I have to thank Aaron Cotnoir for pointing this out.

${ }^{17}$ See Cobreros, Egre, Ripley, van Rooij (2013), inter alia.

${ }^{18}$ Which will also help with the 'just truth' and 'just falsity'.
} 
position on a priori grounds. Cotnoir is not committed to transparency, so I take either one to be a promising option for B4S. If one of those proposals is fruitful, one might expect the concerns to be alleviated - B4 must not lead to trivialism. Let me now show that even with an opaque truth-predicate, or 'tamed' T-schema, B4S cannot meet the exclusivity/exhaustivity constraint.

\section{Third Concern: Collapse}

Let us assume that we have introduced a non-transparent truth-predicate by restricting the T-schema, or a transparent truth-predicate which does not lead to trivialism in a classical framework. Moreover, as we are in classical logic, assume double negation $\neg \neg A \equiv A$ and monotonicity $T[A] \wedge T[A] \equiv T[A] . F[A]$ entails $\neg T[A]$. To see this, remember that by the (restricted) T-schema, the truth-condition for $T[\neg A]$ to be designated needs $\neg A$ to be designated, too. Since we are in classical logic, it follows that $A$ is not designated. Since $\neg T[A] \equiv F[A], T[A]$ must be f, since negation toggles $\mathrm{f}$ and $\mathrm{t}$, and $\neg T[A]$ must be t. To make this graphic, see that, if we are working in a bivalent framework, $T[\neg A]$ and $\neg T[A]$ are equivalent:

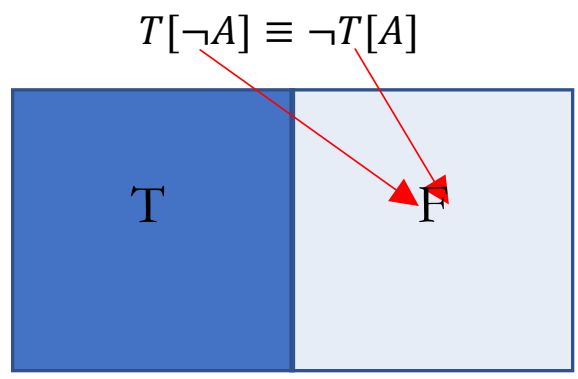

If this reasoning is correct, we again suffer collapse of the catuskoti.

$$
\begin{array}{ll}
\text { Koti1: } & T(A)=T(A) \wedge \neg F(A) \equiv T(A) \wedge \neg \neg T(A) \equiv T(A) \\
\text { Koti2: } & F(A)=F(A) \wedge \neg T(A) \equiv \neg T(A) \wedge \neg T(A) \equiv \neg T(A) \\
\text { Koti3: } & B(A)=T(A) \wedge F(A) \equiv T(A) \wedge \neg T(A) \\
\text { Koti4: } & N(A)=\neg T(A) \wedge \neg F(A) \equiv \neg T(A) \wedge \neg \neg T(A) \equiv \neg T(A) \wedge T(A)
\end{array}
$$

We take the kotis as defined in Priest (2010) on the left side of the equation sign. To formulate the 'just-truth' of the first, and the 'just-falsity' of the second koti, a conjunct is added $(\neg F(A)$ in the case of the first koti, $\neg T(A)$ in the case of the second), to guarantee the exclusivity of the first two kotis. Assuming doublenegation, which is unproblematic in classical logic, we can reformulate $\neg F(A)$ as $\neg \neg T(A)$, eliminating the double-negation, we get $T(A) \wedge T(A)$. Assuming 
monotonicity, which is also unproblematic, we can reformulate the first koti as $T(A)$ - which, for now, is just fine. For koti (2), we write $F(A)$ as $\neg T(A)$. This is unproblematic, since negation works classically, 'just-falsity' is nothing but 'untruth'. Again, have a look at the quadrants above. If $T$ and $F$ exhaust all the possibilities, $F$ is in the right box, such as $\neg T$. Assuming monotonicity, we formulate the second koti as $\neg T(A)$. The right side of the equation is thus how Cotnoir would formulate the kotis in classical bivalent logic. To continue, we also reformulate $F(A)$ in koti (3) as $\neg T(A)$. The first conjunct remains unchanged. In koti (4), we write $\neg F(A)$, assuming double-negation, as $\neg \neg T(A)$, eliminate the double-negation, and are left with $T(A)$. The first conjunct remains unchanged.

What should be apparent now is that the fourth koti is equivalent to the third koti. Both entail koti (1) and (2). This is, koti (3) and (4) are redundant. The classical framework of Cotnoir's proposal has the collapse of the kotis as a consequence. The positive catuskoti cannot reasonably be formulated in B4S because the statuspredicates do not work in a classical framework. Returning to $\operatorname{FDE}(\mathrm{S})$ would thus be an obvious rejoinder. But if we still take Cotnoir's recapture-concerns seriously, we are back to square one - but not if we change our view on what role the catuskoti plays in Nagarjuna's philosophy.

\section{IS THERE REALLY A RECAPTURE PROBLEM?}

There is a way to return to $\mathrm{FDE}(\mathrm{S})$, without facing Cotnoir's problem, if we stop thinking about the catuskoti (and its logic) as providing the basis of the relation of logical consequence for Nagarjuna, and (as does Graham Priest, as confirmed in correspondence) think about the catuskoti simply as the basis of the Madhyamaka metaphysics ${ }^{19}$. Cotnoir assumes that the catuskoti is Nagarjuna's basis of the relation of logical consequence, and that is why $\operatorname{FDE}(\mathrm{S})$ has the weakness it has. Let this be the first way to counter Cotnoir's recapture problem.

Moreover, the catuskoti has some interesting ramifications on common the response to the recapture problem in the study of paraconsitent logic that make the recapture problem disappear and reveal, taking into account the Madhyamaka ontology in the background, where Cotnoir's argument against the formulation of the catuskoti in $\mathrm{FDE}(\mathrm{S})$ goes wrong.

As we now know, taking the material conditional as the conditional is an infelicitous choice for the FDE-ist. Cotnoir himself briefly considers using use the FDE-lattice (with additional resources) as a basis for a relevant conditional. The relevant conditional is known to solve some of the issues with classical inferences as it could be constructed to validate modus ponens, modus tollens, and hypothetical syllogism, but, makes it difficult to model restricted quantification, due to the strength

\footnotetext{
${ }^{19}$ In the same way, the PNC and PEM are metaphysical principles of Aristotle, and his account of logical consequence (syllogistic) is quite independent of this. Thanks to Graham Priest for making me aware of this.
} 
of the conditional. Hence, Cotnoir is right to dismiss this idea. He quotes a case of restricted quantification in the MMK:

Whatever is deceptive is false. Compounded phenomena are all deceptive. Therefore, they are all false. (MMK 13.1)

One way of getting around the recapture problem is Priest's Methodological Maxim (1987:8.4), which, applied to FDE, suggest taking material detachment (i.e. modus ponens), and, more generally, classically valid inferences that are not valid in FDE as acceptable "default inferences", calling them quasi-valid inferences. As we saw in Cotnoir's counterexample to modus ponens, these inferences arise only when truthvalue gluts (i.e. b) or truth-value gluts (i.e. n) occur in the reasoning. Given that, as Priest holds, in vernacular reasoning such things are rare (statistically uncommon), they come with a low a priori probability of obtaining. The idea is now that we are justified in reasoning classically on the assumption that we are neither dealing with gluts, nor gaps. In ordinary discourse, this is certainly a plausible maxim.

Given some usual cat, we are entitled to assume that is has four legs, if we have no reason to think otherwise, or we (at some point) learn otherwise. The same epistemic principle applies to reasoning: If we reason about a situation, we are entitled to think that it is consistent, until we learn otherwise. The belief that the cat has four legs is therefore fallible, as the belief that a given situation or concept is consistent. That is, we may have $\Sigma \vdash A$ but $\Sigma \cup \Pi \Vdash A$. Fallibility due to new information (П) is, then, built into the very notion of logical consequence. Does this strategy work for Nagarjuna?

It does, but surprisingly not for epistemic, but metaphysical reasons: Taking the underlying metaphysics into account, and the ultimate aim of the MMK, which is to establish the lack of svahbava in quite a lot of concepts, we realise that for Nagarjuna, it is the inconsistent situation which is the default position (at least from ultimate reality). Nagarjuna, in fact, has a maximally high a priori probability for dealing with inconsistent concepts in ordinary reasoning, other than the ones we find in "ordinary" logico-mathematical contexts: Change and motion, for example, are inconsistent concepts, according to the MMK. But, if both change and motion are dialethia (i.e. have the truth-value (b), both premises and the conclusion in the instance of the MMK that Cotnoir took to establish the recapture problem are designated, since $D=\{t, b\}-$,When there is change, there is motion. Since there is change in the moving, motion is in that which is moving." (MMK 2.2) aka. modus ponens: $\mathrm{A} \supset \mathrm{B}$, $\mathrm{A} \models \mathrm{B}$ is thus valid in $\mathrm{FDE}(\mathrm{S})$.

What went wrong in Cotnoir's argument? The truth-value assignment $\mathrm{v}(\mathrm{A})=\mathrm{b}$ and $\mathrm{v}(\mathrm{B})=\mathrm{f}$, which makes Modus Ponens: $(\neg \mathrm{A} \vee \mathrm{B}), \mathrm{A} \vDash \mathrm{B}$ invalid in $\mathrm{FDE}(\mathrm{S})$, is an (in the context of the MMK) impossible truth-value assignment. But now, we can argue whether $\mathrm{v}(\mathrm{A})=\mathrm{b}$ and $\mathrm{v}(\mathrm{B})=\mathrm{b}$ is an adequate truth-value assignment. As the MMK is not trying to establish that the concepts in question are pure dialethias, but that they lack svahbava (i.e. are empty) the only plausible truth-value assignment for all the concepts in the MMK is (e), and hence for the modus ponens above the truth-value 
assignment must be $\mathrm{v}(\mathrm{A})=\mathrm{e}$ and $\mathrm{v}(\mathrm{B})=\mathrm{e}$. Whether the modus ponens above is valid, then, hinges on the status of the fifth truth-value (e). In the semantics above, (e) is not member of the set of designated values, and as validity is defined as the preservation of designated values, all reasoning that includes empty concepts (such as the modus ponens above) in invalid. However, in all the arguments with empty concepts that we see in the MMK, we have a preservation of (e). What to make of this, I do not know. I am inclined to think about it as telling us that reasoning is itself empty and lacks svahbava, but I shall leave this to scholars to debate. At least, it is now questionable whether there has ever been a recapture problem, at all.

But what if we are unsatisfied by a paraconsitent/ paracomplete treatment of the catuskoti for other reasons - let them be doctrinal. Can there really be no formulation in classical terms? I shall now suggest a formulation of the catuskoti that I, given the philosophical milieu in which the catuskoti has been predominantly employed, find very compelling.

\section{B4Sx - A PROPOSAL}

Let this not be the end of the story. What we are seeking is an adequate formulation of the catuskoti within a logic in which the crucial inference rules are valid, which avoids trivialism, but does not make the kotis collapse into one another. The logic that I am proposing here is a four-valued Boolean Algebra with the already familiar set of status-predicates. The clue is that negation is an illocutionary act $^{20}$.

Negation as a Speech-Act

Remember that in Westerhoff (2009: 4) we find a different type of negation for koti (4), such that koti (3) is no more deducible from (4). Priest (2010) argues that the "negation-move" is somewhat ad hoc, and while it works for kotis (1-3), it cannot work for koti (4). If we could find a way to implement Westerhoff's analysis of negation into B4, such that koti (3) is no more equivalent to koti (4) and neither of them entails koti (1) and koti (2), we could resist the collapse while staying classical.

Let us first define the behaviour of the external (prasaja) negation ' $X$ ', and its relation to classical negation ' $\neg$ ':

$\times$ does not toggle anything

Neither does $\neg$ entail $\times$, nor $\times$ does not entail $\neg$

Double-negation elimination does not hold for $x \times$

Double negation elimination does neither hold for $X \neg$ nor $\neg \times$

$X$ is considered an illocutionary negation: the speech act of 'denial' 21

\footnotetext{
${ }^{20}$ Illocutionary negation (denial, or denegation) has been defined in Searle (1969).

${ }^{21}$ We thereby extend the notion of the presupposition-cancelling (prasaja) negation to a more general notion, as denial (as a speech-act) can do more than merely cancelling a proposition, e.g. express a lack of evidence or understanding. See Searle (1969: 31-33).
} 
While the first points characterize the behaviour of the external negation, the last point is the most important for the following discussion. Mohanata (2009) and Westerhoff (2009) mention the concept of prasajya pratisedha as a non-relational negation, corresponding to the modern notion of denegation, or illocutionary negation. I follow them and take the prajasa-negation to be a speech act, the speechact of 'denial'. This is plausible, since a denial works, just as the external negation, on the sentential level and is likewise not presupposition-preserving.

It has been suggested that instead of "shrieking", one could "whisper" to regain classicality in paraconsitent contexts ${ }^{22}$. The glut theorist could express classicality by way of conversational implicature. Working with B4S, we don't need to regain classicality. Nevertheless, the core idea is interesting: propositions containing a content can be pre-fixed with an illocutionary operator. One motivation is that using the external negation as an illocutionary act lets us reject the presupposition made by the proposition to be negated. Another motivation is that it corresponds to our epistemic situation in a number of cases. Sometimes we plainly lack the crucial evidence which would make a proposition either true or false, decisively. Certain concepts (perhaps all) the catuskoti, as a prasanga argument, is applied to in the MMK may be of this kind.

Negation as a speech act of denial, regardless of how one accounts for it, can only be restricted to negation of propositions, as, from a semantic viewpoint, in conversations, we do not deny any constituent smaller than a proposition. Or at least if we disagree with some part of a sentence, it would not be expressed as a simple negation qua a speech act of denial, but as an expression of disagreement ${ }^{23}$. In my proposal, I take the illocutionary act to work on the level of truth- and falsityassignments, expressing a quasi-proposition which reads "... the truth of A". The illocutionary act of denial would hence read "I deny (the truth of A/ that the truth of A obtains)". This reflects in the argumentative framework of the dialogs between teacher and student in the Buddhist literature, employing the catuskoti, presenting it with speech-acts, as a prasanga argument. Take the following passage, the translation in Radhakrishnan and Moore (1957: 28) of a conversation between Gotama and an interlocutor about the existence of the Tathagata ${ }^{24}$ (saint) after death. The prominent feature of this conversation is that every truth-assignment or falsity-assignment of the existence of the saint after death is proceeded by an immediate act of denial (in other dialogs, by affirmation).

V1: How is it, Gotama? Does Gotama hold that the saint exists after death,

\footnotetext{
${ }^{22}$ See, inter alia, Sharpio (2004), Priest (2006).

${ }^{23}$ Thanks to Ahmad Jabbar for pressing this point.

${ }^{24}$ There is no onus in the translation of the sanskrit word. It is often thought to mean either "one who

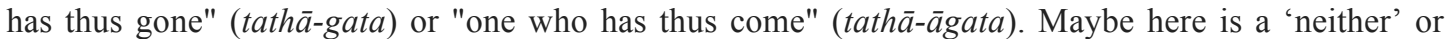
'both' assignment at work too. The Tathagata would thus be the one beyond coming and going, the one who has passed the world of transitory phenomena. Perhaps, the catuskoti is supposed to express that.
} 
and that this view alone is true, and every other false?

G1: Nay, Vacca. I do not hold that the saint exists after death, and that this view alone is true, and every other false.

V2: How is it, Gotama? Does Gotama hold that the saint does not exist after death, and that this view alone is true, and every other false?

G2: Nay, Vacca. I do not hold that the saint does not exist after death, and that this view alone is true, and every other false.

V3: How is it, Gotama? Does Gotama hold that the saint both exists and does not exist after death, and that this view alone is true, and every other false?

G3: Nay, Vacca. I do not hold that the saint both exists and does not exist after death, and that this view alone is true, and every other false.

V4: How is it, Gotama? Does Gotama hold that the saint neither exists nor does not exist after death,

and that this view alone is true, and every other false?

G4: Nay, Vacca. I do not hold that the saint neither exists nor does not exist after death, and that this view alone is true, and every other false.

It is obvious that the Buddha does not give four answers to four questions, he is rather denying that he beliefs in any of those possibilities. This belief could be expressed doxastically, but since we are not concerned with what the Buddha beliefs, but what the Buddha asserts or denies, I take the illocutionary route to be more promising. The act of not-asserting (holding) must hence be equivalent to the act of denying.

This proposal comes with a number of challenges - those that we have encountered already (recapture, collapse and the exclusivity/exhaustivity constraint) plus some that are specific to this formulation:

First Challenge: Priest (2010) is right in making explicit that appeal to speech acts inside propositional contexts is pointless. The first koti formulated with the illocutionary negation of the second conjunct $A \wedge \times \neg A$ in a logic without statuspredicates does not make sense. Taking the second koti as one proposition, we have, by this formulation, a speech-act as a part of the content of the proposition, but this is not how a speech-acts work. The same goes for the second koti. For my proposal to be successful, this has to be avoided. Let this be the first challenge.

Second Challenge: On Westerhoff's account, $\neg A$ entails $\times A$, as thoroughly explained in $\S 1$. "The bird is not a crane" entails "It is not the case that this bird is a crane, but not vice versa. If this is so, the fourth koti, formulated as $\times(A \vee \neg A)$, cannot hold. $A$ cannot both hold and fail to hold. The fourth koti must have an intelligible formulation in B4Sx

Third Challenge: Although it shall not be decisive, it would be of advantage if the proposed logic could, unlike its friend $\mathrm{B} 4$, accommodate the negative catuskoti as well.

The Catuskoti in B4Sx 
A logic built on B4, which has the status-predicates, and the illocutionary negation as a supplemented operator will be called B4Sx. As already mentioned, there is no direct textual evidence that there are two different negations at work in the catuskoti. Yet, I take Westerhoff's (2010) considerations that the catuskoti and the negations therein have been be convincing. But, since every negation in the catuskoti is potentially ambiguous, I will formulate the catuskoti with the illocutionary negation only. Regarding the fact that the most common use of the catuskoti is within a conversational setting, the idea of exclusively utilizing illocutionary acts in a modelling seems reasonable to me. The suggested formulation of the catuskoti in B4Sx is the following:

$$
\begin{aligned}
& \text { Positive Catuskoti 1.0 } \\
& \text { Koti 1: } T(A)=T(A) \wedge \times F(A) \\
& \text { Koti 2: } F(A)=F(A) \wedge \times T(A) \\
& \text { Koti 3: } B(A)=T(A) \wedge F(A) \\
& \text { Koti 4: } N(A)=\times T(A) \wedge \times F(A)
\end{aligned}
$$

To formulate the negative catuskoti, I take the denial of all the alternatives to be expressible by a speech-act as well. Let this speech-act be 'silence', or more appropriate to the Madhyamika context; 'ineffability', expressed by the $\otimes$-operator, which denies the existence of 'svabhava' for what is presupposed in the kotis: call it the sunyata-operator. It is important to note that 'silence' itself doesn't classify as a speech act, albeit a form of communication. It is not literal silence about $A$, as in not talking where talk is expected. What the ' $\otimes$ ' is supposed to express is a statement about the ineffability (being silent about) of the status of $A$. We want to apply the $\otimes$-operator to $A$ whenever $A$ is not part of our language, this is, whenever it exceeds the conventional realm, and with it conceptual language and thought. There is a significant strand of the Buddhist tradition that explicitly asserts that claims about ultimate reality are beyond language ${ }^{25}$, hence, we do not want to assert something about ultimate reality, so I define ' $\Theta$ ' in terms of ' $x$ ', denying assertions about the truth or falsehood of $A$. By denying $T(A)$ and denying the denial of $F(A)$, one does not affirm $T(A)$ or $F(A)$, but remains silent about it.

\section{Negative Catuskoti 1.0}

Koti 1: $\otimes T(A)=\times(T(A) \wedge \times F(A))$

\footnotetext{
${ }^{25}$ In the Indian Buddhist tradition, there is a lively debate about the question whether such statements as "everything is empty" or "nothing exists by svabhāva" are correct expressions of (parts of) ultimate reality. I take it to be a plausible interpretation of the MMK, and shall refrain from going into detail on this discussion. This might have the downside that my model for the catuskoti only works in the context of Nagarjuna's philosophy. Even more so, saying that ultimate reality is (always) beyond language and thought, and that statements about ultimate reality are ineffable is in the context of Chinese Buddhist philosophy and its derivatives certainly contentious. Dogen, for example, literally denies the ineffability of ultimate reality, and so does much of Tientai thought. Thanks to Jan Westerhoff for pressing the former point, and an anonymous referee for pressing latter.
} 
Koti 2: $\otimes F(A)=\times(F(A) \wedge \times T(A))$

Koti 3: $\otimes B(A)=\times(T(A) \wedge F(A))$

Koti 4: $\otimes N(A)=\times(\times T(A) \wedge \times F(A))$

One important note on the semantics for those speech acts: illocutionary acts are not part of the content of a sentence, but indicate the force with which a sentence is uttered. It therefore makes no sense to embed a sentence with a prefixed force operator within a more complex sentence, as we have discussed it before. However, in defining ' $\otimes$ ' above, I regularly do embed a sentence with a prefixed force operator within a more complex sentence. What is to make of this? We have to tweak speech-act theory a little here, to make sense of this formulation:

As we are in a conversational setting, and it is not uncommon that in a conversational setting things one has affirmed or denied earlier are taken back, corrected, or emphasized. We can think of an emphasis, for example, as a speech-act which governs over speech-acts one has performed earlier, without performing the speech-act again, but simply by referring to it. The earlier speech-act the manifesting speech-act is referring to is not a force in its own right anymore, but has taken a propositional form which can be prefixed with a force operator (e.g. emphasis). The same thing happens in the formulation of the negative catuskoti with the $\otimes$-operator. The denial which is embedded in the complex sentence and prefixed with the illocutionary act of denial has lost its force and illocutionary power, but can still be referred to, without being "illocutionarily" effective. Let us formulate the ineffective illocutionary act of denial as $x^{\text {ineffective }}$, and we can model the negative catuskoti without the obscure use of speech-acts inside speech-acts.

Negative Catuskoti 2.0

Koti 1: $\otimes T(A)=\times\left(T(A) \wedge \times^{\text {ineffective }} F(A)\right)$

Koti 2: $\otimes F(A)=\times\left(F(A) \wedge \times^{\text {ineffective }} T(A)\right)$

Koti 3: $\otimes B(A)=\times(T(A) \wedge F(A))$

Koti 4: $\otimes N(A)=\times\left(\times^{\text {ineffective }} T(A) \wedge \times{ }^{\text {ineffective }} F(A)\right)$

It is important to note that ' $\otimes$ ' is not a mere rejection. It is tempting to interpret the negative catuskoti as a rejection of all possibilities, but Nagarjuna thinks that everything is empty of self-being (svahbava), which is not the same as a simple denial of the self-being. It is not as though every statement about ultimate reality has to be rejected - Nagarjuna wasn't a mystic. See what MMK XXIV: 18 tells us:

Whatever is dependently co-arisen

That is explained to be emptiness.

That, being a dependent designation,

Is itself the middle way.

Interpret "That is explained to be emptiness" as ascribing 'emptiness' to something in a positive illocutionary act of ascribing all the possibilities of the catuskoti a further 
status, which is distinct from $T(A) \vee F(A) \vee B(A) \vee N(A)$. But to do that, all the possibilities have to be (implicitly) denied. Where Priest (2010) adds another statuspredicate $(\mathrm{E})$, I interpret the affirmation of 'emptiness' as an illusionary act which denies all $T(A) \vee F(A) \vee B(A) \vee N(A)$ and by that ascribes ' $\otimes$ ' to them. Hence, the illocutionary act, expressed by ' $\otimes$ ' is both a (implicit) denial (of all the kotis) and an (explicit) affirmation (of emptiness). This behaviour of ' $\otimes$ ' is perfectly captured by a speech-act, albeit an unconventional one ${ }^{26}$, which thus reads "I explicitly affirm the emptiness (sunyata) of $A$ and implicitly deny the self-being (svahbava) of $A$."

$$
\begin{gathered}
\text { Implicit denial of all kotis: } \\
\quad \equiv(T(A) \vee F(A) \vee B(A) \vee N(A)) \\
\text { Explicit affirmation of Emptiness } \otimes(A)
\end{gathered}
$$

The illocutionary acts create a (non-gappy or glutty) bivalence of acceptance/or denial and, to make this more apparent, one could read the positive catuskoti alternatively with an assertion-operator ' \# ' which, pace Searle (1969), stand for the assertive illocutionary act. \# $T(A)$ reads "I assert that $T(A)$." The \#-operator is redundant in this case, but nevertheless its behaviour can be defined:

\# doesn't toggle anything.

\# does iterate.

Double-affirmation elimination holds for \#\#.

$\# \times$ then $\times$, but not $\times \#$ then $\times$.

\# is interpreted as an illocutionary affirmation

Positive Catuskoti 2.0

Koti 1: $T(A)=\# T(A) \wedge \times F(A)$

Koti 2: $F(A)=\# F(A) \wedge \times T(A)$

Koti 3: $B(A)=\#(T(A) \wedge F(A))$

Koti 4: $N(A)=\times(T(A) \wedge F(A))$.

\section{Regarding Recapture}

First of all, note that B4Sx is fully classical with respect to the crucial inference rules, as we are in Four-Valued Boolean Algebra. The illocutionary operators do not

\footnotetext{
${ }^{26}$ One might wonder here, if speech-acts do really work in this way. The problem is that illocutionary acts are not part of the content of a sentence, but indicate the force with which a sentence is uttered. There is, so orthodox speech-act theory, no force that corresponds to 'explicitly affirmation the emptiness and implicitly deny the self-being'. Thanks to Graham Priest for pointing this comment. This observation is certainly correct, but as orthodox speech-act theory most probably doesn't include the illocutory forces of ancient India, and we can guess that statements about emptiness have an exceptional status, let us just think of $\otimes$ as an illocution, and let us think that there is a corresponding force.
} 
interfere with modus ponens, modus tollens, disjunctive syllogism, or any other classical inference rule which we can find in the MMK since there is no entailment from ' $\neg$ ' to ' $X$ ', or ' $X$ ' to ' $\neg$ '. We can say that Cotnoir's recapture problem seems to be solved. Let us now verify that B4Sx can also ground the logic for the catuskoti, without collapse.

\section{Regarding the Exclusivity/Exhaustivity Constraint}

Regarding the first two kotis: To express the 'just-truth' and 'just-falsity' of the first two kotis, the respective dual is negated with the illocutionary negation ' $x$ '. Having a status-predicate governing our proposition we have left the propositional context. It thus makes sense to formulate the kotis in that way. In the case of the first koti it states the truth of $A$, and denies the falsity of $A$, which is just like stating the just-truth of $A$. The same goes for the 'just-falsity' in koti (2). It says that the falsity of $A$ obtains, while the truth of $A$ does not.

Regarding the last koti: I take $\times T(A) \wedge \times F(A)$ to be a natural formulation of the not-obtaining of neither the truth nor the falsity of $A$. Whereas to assert that it is not the case that $A$ does hold and does not hold does not make sense, it makes good sense to assert that neither the truth nor the falsity of $A$, while making no statement about the ontological nature of $A$ itself. The last koti makes good sense in this formulation.

\section{Regarding Collapse}

The kotis in B4Sx do not collapse. Contraposition: $\times T[A] \leftrightarrow \times A$ is not valid in B4Sx. To deny truth of $A$ does not imply denying that $A$ does not obtain at all, the same goes for the other direction. $T(\times A)$ is not equivalent to $\times T(A)$, since $T(\times A)$, as I have formulated it, doesn't make sense - the $\times$-operator works on the level of truth-predicates only. Neither is $T(\neg A)$ equivalent to $\times T(A)$, since $\times T(A)$ leaves open the possibility that $A$ does obtain, while $T(\neg A)$ does not allow for this possibility. Again, this is because ' $\times$ ', as I construe it, works in the metalanguage of truth-predicates, and ' $\neg$ ' in the object language.

In the light of the aforementioned, we can see why the catuskoti does not collapse in B4Sx. The first koti $T(A) \wedge \times F(A)$ is equivalent to $T(A) \wedge \times \neg T(A)$. Since double-negation elimination does not hold for ' $X \neg$ ', we cannot reduce the first koti to $T(A)$. The transformation stops there. The second koti $F(A) \wedge \times T(A)$ is equivalent to $F(A) \wedge \times \neg F(A)$. We cannot reduce this to $F(A)$ for the same reason. The transformation stops there. The fourth koti $\times T(A) \wedge \times F(A)$ is equivalent to $\times \neg F(A) \wedge \times \neg T(A)$, and the third koti $T(A) \wedge F(A)$ is equivalent to $\neg F(A) \wedge \neg T(A)$, but neither is $\times \neg F(A) \wedge \times \neg T(A)$ equivalent to, nor does it entail $\neg F(A) \wedge \neg T(A)$. The former denies the not-obtaining of the truth and falsity of $A$, the latter, which could be read with an \#-operator, asserts the obtaining of both the truth and the falsity of $A$ - two very different things. Form neither 
$\times \neg F(A) \wedge \times \neg T(A)$, nor $\neg F(A) \wedge \neg T(A)$ we can entail $T(A) \wedge \times \neg T(A)$ or $F(A) \wedge \times \neg F(A)$. The catuskoti does not collapse!

\section{CONCLUSION}

We have seen several attempts to find a logic for the catuskoti with classical operators. Priest has argued that none of those formulations is adequate. He suggested $\mathrm{FDE}(\mathrm{S})$ as the logic for the positive catuskoti, and $\mathrm{FDE}(\mathrm{e})$ for the negative. Cotnoir challenged $\operatorname{FDE}(\mathrm{S})$ with the classical recapture problem. As it turned out, Cotnoir's suggested logic (even if drastically altered) makes the catuskoti collapse as well. Taking his concerns seriously, I have introduced a natural extension of Cotnoir's proposal which builds on the idea of treating the negations in the catuskoti as an (unorthodox) speech-act. With this semantics, the recapture problem is alleviated and a collapse of the four corners of the catuskoti is successfully avoided.

\section{ACKNOWLDEGEMENTS}

I want to use this opportunity to thank Graham Priest for our 'enlightening' correspondence on this material and many most helpful remarks on an earlier draft. Furthermore, I am indebted to Aaron Cotnoir, Ahmad Jabbar, Makan Nojoumian, Kevin Scharp, Fenner Tanswell, Jan Westerhoff, Alastair Wilson and an anonymous referee for adjuvant comments. Versions of this paper have been given at the Asian Philosophical Texts conference at the Université libre de Bruxelles and the Taiwanese Philosophical Logic Colloquium at Taiwan National University. I am indebted to the audiences and would like to express my gratitude.

\section{REFERENCES}

Anderson, A., Belnap, N. (1975), Entailment: The Logic of Relevance and Necessity. (Princeton: Princeton University Press).

Beall, JC. (2013), "LP+, K3+, FDE+, and their 'classical collapse' ", Review of Symbolic Logic 6: 742-754.

Cotnoir, A. (2015), Nagarjuna's Logic, in Graham Priest; Koji Tanaka; Y Deguchi; and Jay Garfield (eds), The Moon Points Back (Oxford: Oxford University Press), 176-188.

Cobreros, P.; Egre, P.; Ripley, D.; and Van Rooij, R. (2013), "Reaching transparent truth", Mind 122: 841-866.

Deguchi, Y., and Garfield, J. (2008), "The Way of the Dialetheist: Contradictions in Buddhism", Philosophy East \& West 58: 395-402.

Garfield, J.; Deguchi, Y.; and Priest, G. (2009), "Mountains are just Mountains", in D'Amato, D,; Garfield, J.; and Tillemans, T. (eds), Pointing at the Moon: Buddhism, Logic, Analytic Philosophy (Oxford: Oxford University Press), 71-82.

Horn, L. (1989), A Natural History of Negation (Chicago: University of Chicago Press).

Kreutz, A. (forthcoming), From Tetralemma to Koan.

Priest, G. (2001), Introduction to Non-Classical Logic (Cambridge: Cambridge University Press). 
- (2006), In Contradiction (Oxford: Oxford University Press).

- (2010), "The Logic of the Catuskoti", Comparative Philosophy 1.2: 24-54.

- (forthcoming), The Fifth Corner of Four: An Essay on Buddhist Metaphysics and the Catuskoti. (Oxford: Oxford University Press).

Radhakrishnan, S., and Moore, C. (eds) (1957), A Sourcebook in Indian Philosophy (Princeton: Princeton University Press).

Routley, R. (1969), “The Need for Nonsense”, Australasian Journal of Philosophy 47: 367384.

Mohanta, D. (2009), "The use of Four-Cornered Negation and the denial of the Law of Excluded Middle in Nāgārjuna's logic", in A. Schumann (ed.), Logic in Religious Discourse (Paris \& Frankfurt: Ontos Verlag), 44-53.

Scharp, K. (2018), "Shrieking in the Face of Vengeance", Analysis 78.3: 454-463.

Searle, J. (1969), Speech Acts (Cambridge: Cambridge University Press).

Sharpio, S. (2004), "Simple Truth, Contradiction, Consistency", in Priest, G.; Beall, JC; and Armour-Grab, B. (eds), The Law of Non-Contradiction: Philosophical Essays (Oxford: Oxford University Press).

Sideritis, M., and Katsura, S. (2013), Nagarjuna's Middle Way. Mulamadhyamakakarika. (Wisdom Publication).

Westerhoff, J. (2007), "The Madhyamaka concept of svahbava: ontological and cognitive aspects", Asian Philosophy 17.1: 17-45.

- (2009), Nagarjuna's Madhyamaka: A Philosophical Introduction (Oxford: Oxford University Press). 